\title{
O comportamento do usuário no processo de difusão de fake news: reflexões sobre o processo de comunicação nas plataformas digitais
}

\author{
User behavior in the fake news diffusion process: reflections on the \\ communication process on digital platforms
}

\author{
El comportamiento del usuario en el proceso de difusión de fake news: \\ reflexiones sobre el proceso de comunicación en las plataformas digitales
}

\author{
Angelo Sastre ${ }^{l}$ \\ Juliano Maurício de Carvalho ${ }^{2}$
}

\begin{abstract}
Resumo
A comunicação, conforme observado por Maffesoli (2003), é uma ferramenta de "religação" entre os indivíduos e o elemento que funciona como um "cimento social" ao unir pessoas, interesses e crenças. Nesse sentindo, o presente artigo busca discutir sobre como o comportamento do usuário, refletindo esse processo de identificação com o grupo por meio das novas tecnologias, pode interferir na difusão da fake news. Dessa forma, observamos que a cultura das mídias sociais fortalece a construção de mitos e gera referências sociais que distorcem o processo de comunicação em torno de um mecanismo de (in)formação com base em padrões pré-estabelecidos. Assim, ampliamos a reflexão por meio do conceito do "além-homem", de Nietzsche (2005a), e o Mito de Superman, Eco (2004), já que é necessário fugir dos "filtros" tecnológicos, estéticos e sociais para evitar as "ilusões" construídas e compartilhadas, até de forma ingênua, por meio das redes construídas nas diferentes plataformas de comunicação digital.
\end{abstract}

Palavras-chave: Fake News. Comunicação digital. Mídias sociais. Comportamento do usuário. Novas tecnologias.

\begin{abstract}
Communication, as observed by Maffesoli (2003), is a tool of "reconnection" between individuals and the element that functions as a "social cement" in uniting people, interests and beliefs. In this sense, this article seeks to discuss how user behavior, reflecting this process of identification with the group through new technologies, may interfere with the diffusion of fake news. Thus, we observe that the culture of social media strengthens the construction of myths and generates social references that distort the communication process around a mechanism of (in)formation based on pre-established standards. Thus, we broadened our reflection through Nietzsche's concept of the "beyond-man" (2005a) and the Superman Myth (2004), since it is necessary to escape the technological, aesthetic and social "filters" to avoid "Illusions" built and shared, even naively, through the networks built on the different platforms of digital communication.
\end{abstract}

Keywords: Fake News. Digital communication. Social media. User behavior. New technologies.

\section{Resumen}

La comunicación, según lo observado por Maffesoli (2003), es una herramienta de "religación" entre los individuos y el elemento que funciona como un "cemento social" al unir personas, intereses y creencias. En este sentido, el presente artículo trata de discutir sobre cómo el comportamiento del

\footnotetext{
${ }^{1}$ Mestre em Sociologia pela UNESP-Araraquara. e-mail: angelosastre@ gmail.com

${ }^{2}$ Doutor em Comunicação. Docente nos programas de pós-graduação em Comunicação e Mídia e Tecnologia da Universidade Estadual Paulista "Júlio de Mesquita Filho"(UNESP). e-mail: juliano.mauricio@unesp.br
} 
usuario, reflejando ese proceso de identificación con el grupo a través de las nuevas tecnologías, puede interferir en la difusión de fake news. De esta forma, observamos que la cultura de los medios sociales fortalece la construcción de mitos y genera referencias sociales que distorsionan el proceso de comunicación en torno a un mecanismo de (in)formación basado en patrones preestablecidos. Así, ampliamos la reflexión por medio del concepto del "ultra-hombre", de Nietzsche (2005a), y el Mito de Superman, Eco (2004), ya que es necesario huir de los "filtros" tecnológicos, estéticos y sociales para evitar las " "Ilusiones" construidas y compartidas, hasta de forma ingenua, por medio de las redes construidas en las diferentes plataformas de comunicación digital.

Palabras-clave: Fake News. Comunicación digital. Redes sociales. Comportamiento del usuario. Nuevas tecnologías.

\section{INTRODUÇÃ̃O}

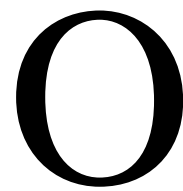

processo de comunicação é uma característica da convivência em grupo e suas formas refletem a cultura e as referências de sua época. Nesse sentido, observamos que os meios de comunicação podem sofrer alterações e serem adaptados a diferentes ferramentas e plataformas de difusão. No entanto, a intencionalidade do homem continua sendo a busca pela aceitação no grupo, compartilhamento de conhecimentos e reconhecimento entre os demais membros da comunidade.

Esse contexto reforça o conceito de Maffesoli (2003) que aponta a comunicação como uma ferramenta de religação entre os indivíduos ou o "cimento social", já que fortalece o conceito de sociabilidade e da necessidade da relação com o outro.

"Nesse sentido, a ideia de individualismo não faz muito sentido, pois cada um está ligado a outro pela mediação da comunicação. O importante é o primum relationis, ou seja, o princípio de relação que me une ao outro.” (MAFFESOLI, 2003, p. 13)

Por outro lado, Castells (2005) aponta que as pessoas possuem autonomia para organizar e decidir seu comportamento, mas as mensagens enviadas pela mídia interagem com seus receptores de forma intencional.

Porém, enfatizar a autonomia da mente humana e dos sistemas culturais individuais na finalização do significado real das mensagens recebidas não implica que os meios de comunicação sejam instituições neutras, ou que seus efeitos sejam desprezíveis. Pelo menos mostram os estudos empíricos, a mídia não é uma variável independente na indução de comportamentos. Suas mensagens, explícitas ou subliminares, são trabalhadas, processadas por indivíduos localizados em contextos sociais específicos, dessa forma modificando o efeito pretendido pela mensagem. (CASTELLS, 2005, p. 421).

Esse paradoxo entre a autonomia do usuário e a intencionalidade da mídia, mesmo que de forma implícita, reflete a ideia de influência e a construção dos "padrões sociais", que no 
passado foram fortemente definidos com base em controles e princípios religiosos como criticado por Nietzsche.

Considerando esse contexto, observamos que o comportamento do usuário manteve essa postura, entretanto, a influência passa a ocorrer na plataforma digital por meio das tecnologias e técnicas de direcionamento dos conteúdos. Assim, é possível considerar que essa autonomia é irreal, ou seja, o usuário possui a sensação de liberdade, mas está vinculado a padrões préexistentes, mesmo que não tenha consciência plena da situação intermediada pelos algoritmos, "filtros" e padrões de programação.

Diante desse cenário é possível adaptar as observações de Nietzsche (1984) ao analisar a situação da sociedade e provocar a reflexão por meio do conceito do "super-homem" ou "além-homem"3, que defende a criação de um modelo de pensamento e comportamento baseado na revisão dos velhos ideais e criação de novos em um processo contínuo de superação das influências e padrões pré-estabelecidos na sociedade.

O homem é superável. Que fizestes para o superar? Até agora todos os seres têm apresentando alguma coisa superior a si mesmos; e vós, quereis o refluxo desse grande fluxo, preferis tornar ao animal, em vez de superar o homem? Que é o macaco para o homem? Pois é o mesmo que deve ser o homem para Super-homem: uma irrisão ou uma dolorosa vergonha. Percorrestes o caminho que medeia do verme ao homem, e ainda em vós resta muito do verme. Noutro tempo fostes macaco, e hoje o homem é ainda mais macaco do que todos os macacos. Mesmo o mais sábio de todos vós não passa de uma mistura híbrida de planta e de fantasma. Acaso vos disse eu que vos torneis planta ou fantasma? (NIETZSCHE, 1984, p. 13)

Essa característica social, de criar e manter os vínculos com padrões pré-estabelecidos pela comunidade, contribui para a compreensão da sinergia gerada pelas plataformas de comunicação e grupos criados nas mídias sociais, onde a identificação entre seus membros passa a ser a principal fonte de referência.

Dessa maneira observamos como a construção de preferências passa a ser orientada pelos mecanismos tecnológicos, que utilizam as informações exploradas e mencionadas pelos usuários como dados relevantes na seleção de conteúdo. Essa sistemática, por sua vez, limita o

\footnotetext{
${ }^{3} \mathrm{O}$ termo original utilizado por Nietzsche em alemão é "Übermensch" que é um termo de origem medieval, derivado de "Übermenschliches" traduzido como sobre-humano, no sentido de sobrenatural. No entanto, a tradução para o português foi convencionada como "Super-homem", mas alguns autores e tradutores defendem que o termo mais adequado é "além-homem" (como no inglês Beyond-Human, cuja a tradução é além-do-humano). Dessa forma, o presente artigo utiliza as duas formas respeitando o termo mencionado em cada tradução citada nas referências.
} 
acesso a outras fontes reforçando a importância do material compartilhado no "universo" criado e distribuídos entre os contatos frequentes.

Essa lógica ganha força ao considerar, como menciona Maffesoli (2003), que o fluxo de informação ganha mais importância sob o aspecto relacional que fortalece a concepção da utilidade e credibilidade dos grupos ou universos segmentados.

\begin{abstract}
Mesmo, portanto, que a informação seja apropriada e instrumentalizada temporariamente, a potência subterrânea tende a impor a força comunicativa (relacional) dessa informação, ou seja, a capacidade de estabelecer comunhão e partilha de algo entre indivíduos e grupos. Como se diz no jargão da sociologia da comunicação, a emissão não pode controlar efetivamente a recepção. A instrumentalização da informação aconteceria se essa informação fosse total, global, capaz de dar nova substância ao velho fantasma do universalismo. Ora, na prática, a informação só consegue unir microgrupos, microcosmos, universos segmentados. (MAFFESOLI, 2003, p. 15).
\end{abstract}

A condição observada de vínculo aos interesses, ideais e referências fortalecidas pelo conteúdo compartilhado nos grupos e espaços socializados nas plataformas digitais pode ser compreendido por meio da adaptação do esforço mencionado por Nietzsche (2005a), ao refletir que o "além-homem" precisa se desvencilhar dos valores de massa mesmo diante dos eventuais conflitos e restrições proporcionadas por essa libertação.

De acordo com essas reflexões, o processo cultural e, consequentemente, o comportamento humano, são limitações pessoais e transitórias, ou seja, o homem pode ser considerado um elemento variável no processo e a posição do "além-homem" é a concretização desse processo de superação de seu estado de imobilidade, fragilidade e dependência social e cultural em relação ao conteúdo e ideais compartilhados.

O homem é uma corda, atada entre o animal e o além-do-homem - uma corda sobre um abismo. Perigosa travessia, perigoso a-caminho, perigoso olharpara-atrás, perigoso arrepiar-se e parar. O que é grande no homem é que ele é uma ponte e não um fim: o que pode ser amado no homem, é que ele é um passar e um sucumbir. (NIETZSCHE, 2005a, p. 211).

Nessa referência podemos considerar a importância do comportamento do usuário no fluxo de informação, já que ele atua como uma "ponte" ou um "meio" (mídia) no processo de comunicação e que suas ações são pontuais ou temporárias podendo ser alteradas por diversos fatores, informações e cenários. 
Por outro lado, essa dinâmica reforça a reprodução dos padrões que são incorporados na construção de seus perfis e no sistema de interação entre os membros do grupo, que buscam alcançar o status desejado por meio do reconhecimento exterior.

Assim sendo, como observado por Maffesoli (2003), a qualidade do conteúdo passa a ser um componente secundário no fluxo de informações, onde as ações, hábitos e práticas de caráter interativo são considerados fundamentais na formatação da imagem pública junto aos demais membros de grupos e contatos nas plataformas e mídias sociais.

Por mais que isso horrorize os críticos politicamente corretos, as pessoas não querem só informação na mídia, mas também e fundamentalmente ver-se, ouvir-se, participar, contar o próprio cotidiano para si mesmas e para aqueles com quem convivem. A informação serve de cimento social. (MAFFESOLI, 2003, p. 15).

\section{ESTRUTURA NARRATIVA E CONSTRUÇÃO DAS MENSAGENS}

Mesmo considerando que a atitude e comportamento do usuário seja evidente e determinante no processo de comunicação, inclusive interferindo na intencionalidade e na recepção da mensagem, não é possível atribuir como único responsável pela difusão de informações distorcidas ou pelas fake news ${ }^{4}$.

Esse posicionamento será uma visão limitada e simplista de um processo complexo que envolve, entre outros fatores, a estrutura narrativa e a construção simbólica das mensagens por meio de elementos representativos em um contexto pré-definido.

Nesse sentido, é importante considerar que a apresentação do conteúdo segue uma lógica de envolvimento que estimula a participação do usuário e, que por sua vez, é retroalimentada pelo critério de proximidade de seus contatos que retransmitem o conteúdo por reconhecerem os princípios, interesses e ideias compartilhados com o emissor e avaliados como relevantes para o processo de interação na comunidade digital.

A sociedade da informação, portanto, pode até fazer crer que o mais importante são os seus jornais, televisões e rádios, mas no fundo o que conta é a partilha cotidiana e segmentada de emoções e de pequenos

\footnotetext{
${ }^{4}$ Fake News é definido pelo Ethical Journalism Network, entidade sem fins lucrativos com sede em Londres (Inglaterra), como "uma informação deliberadamente fabricada e publicada com a intenção de enganar os outros em falsidades ou em duvidar de fatos verificáveis". (WHITE, A. Fake news: it's not bad journalism, it's the business of digital communications. Londres: Ethical Journalism Network, 2017. Disponível em: <http://ethicaljournalismnetwork.org/fake-news-bad-journalism-digital-age>. Acesso em: 03.mai.2017).
} 
acontecimentos. Mesmo na internet o aspecto interativo predomina sobre o utilitário. De alguma forma, o mais interessante é o grau zero da informação. Nisso tudo, claro, há informação. No entanto, o essencial está em reconhecerse, em ver-se, em fazer parte de uma comunidade presencial ou virtual. (MAFFESOLI, 2003, p. 15).

Com base nesse princípio observamos como algumas características se tornam marcantes e presentes na estrutura das informações disseminadas pelos conteúdos de fake news que, entre outras coisas, apresentam uma conotação sensacionalista e espetacular, foca em temas da atualidade e com ampla popularidade e busca elementos como discurso e imagens em tom de denúncia ou prevenção de situações de risco.

Essa situação alarmista é o primeiro "gatilho" que exerce influência sobre o comportamento do usuário, já que para ser um membro presente e reconhecido pela comunidade e/ou grupo é necessário estar presente e para conquistar relevância ou status é necessário reforçar o aspecto de interatividade de forma constante.

Podemos considerar como segundo "gatilho" a identificação com o conteúdo narrado e difundido, ou seja, uma situação de ameaça, injustiça, denúncia ou prevenção de riscos em potencial.

Assim, chegamos ao terceiro "gatilho" que é demonstrado como o mais sensível, ou seja, o ponto determinante que é a atribuição de credibilidade pela origem da transmissão (o contato conhecido) e não pela fonte de informação que está sendo compartilhada nas plataformas e mídias sociais.

Portanto, é possível fazer a relação entre as situações apontadas por Nietzsche, ao propor a necessidade de busca do "além-homem", para superar os velhos padrões impostos pela sociedade e que nos direcionam de uma forma previsível.

Como aponta Eco (2004) esse processo gera uma situação de "mitificação" da informação provocando um comportamento e uma perspectiva de envolvimento espontâneo sem a racionalização dos fatos e contextos.

O problema com que nos pretendemos defrontar exige uma definição preliminar e, em suma, aceitável de "mitificação" como simbolização incônscia, identificação do objeto com uma soma de finalidades nem sempre racionalizáveis, projeção na imagem de tendências, aspirações e temores particularmente emergentes num indivíduo, numa comunidade, em toda uma época histórica. (ECO, 2004, p. 239). 
Essas referências mencionadas por Eco (2004) podem ser identificadas facilmente em duas postagens recentes que circularam em grupos de WhatsApp e em mídias sociais como Facebook e Twitter.

No primeiro episódio o caráter alarmista foi a circulação de um áudio em que um suposto caminhoneiro anunciava uma nova paralisação da categoria, uma semana após o encerramento do movimento. A difusão da informação foi impulsionada pelos usuários em razão de reforçar o temor de desabastecimento e das demais situações enfrentadas pela população durante o movimento da categoria. A sensação de relevãncia da informação associada ao fato de a mensagem ser fortalecido por um áudio, que é visto como um elemento de "comprovação", e a identificação do emissor (responsável pelo compartilhamento), que geralmente é uma pessoa do círculo de contatos ou "confiável”, intensificam o estímulo do compartilhamento entre os demais contatos, perfis e comunidades virtuais.

Um outro exemplo dessa situação vivenciada recentemente foi a denúncia de que uma rede nacional de supermercados estaria vendendo ovos de plástico produzidos artificialmente por uma indústria chinesa. Além das características mencionadas anteriormente, a "denúncia" vinha acompanhada de um vídeo demostrando a "veracidade" e fortalecendo a mitificação produzida dos riscos em relação a saúde pública e que foram impulsionadas pelos aspectos relacionais identificados por Maffesoli (2003).

Essas duas narrativas reforçam o conceito de Nietzsche (2005b) sobre a universalização da história como referência no processo de identificação e mitificação das comunicações de massa, que na atualidade ganham essa proporção pelo alcance das plataformas e mídias sociais e não, necessariamente, pela veiculação na grande imprensa ou em veículos de alcance popular como a rádio e a televisão.

Se em contrapartida, as doutrinas do vir-a-ser soberano, da fluidez de todos os conceitos, tipos e espécies, da falta de toda diferença cardeal entre homem e animal - doutrinas que considero verdadeiras, mas mortais -, no furor de instrução agora costumeiro, forem lançadas ao povo ainda durante uma geração, ninguém deve admirar-se se o povo naufragar no egoisticamente pequeno e mísero, na ossificação e no amor-próprio, ou seja, se se desagregar e deixar de ser um povo: em lugar disso, então, talvez sistemas de egoísmo individuais, irmandades para fins de pilhagem contra os não-irmãos, e semelhantes criações de vulgaridade utilitária entrarão em cena no palco do futuro. Para preparar o caminho a essas criações, basta que se continue a escrever a história do ponto de vista das massas e a procurar nela aquelas leis que podem ser derivadas das necessidades das massas, portanto as leis de movimento das mais baixas camadas de lama e de argila da sociedade (NIETZSCHE, 2005b, p. 286). 


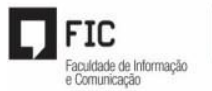

O contexto observado reforça o poder de influência e a relação de padronização dos usuários em relação aos valores e ações esperadas pelo grupo, que são exercidos no processo de exposição, manutenção e identificação com os demais no ambiente virtual.

Assim, retomamos o conceito paradoxal entre a autonomia do usuário e a intencionalidade da mídia, já que a estrutura apontada explora as características de similaridade entre os usuários e acaba direcionando conteúdos específicos que reforçam as ideias, princípios e crenças.

Como apontado por Eco (2004), o nivelamento social provoca a generalização ou a criação de premissas coletivas que insinuam a concessão de poder, porém, ocorrem de forma controlada e direcionada por diferentes situações e modelos.

Mas numa sociedade particularmente nivelada, onde as perturbações psicológicas, as frustrações, os complexos de inferioridade estão na ordem do dia; numa sociedade industrial onde o homem se torna número no âmbito de uma organização que decide por ele, onde a força individual, se não exercitada na atividade esportiva permanece humilhada diante da força da máquina que age pelo homem e determina os movimentos mesmos do homem - numa sociedade de tal tipo, o herói positivo deve encarnar, além de todo limite pensável, as exigências de poder que o cidadão comum nutre e não pode satisfazer. (ECO, 2004, p. 246-247).

A realidade demonstrada pode ser observada por meio da análise do caso envolvendo as fake news relacionadas a vereadora Marielle Franco (PSOL-RJ), que após ser executada a tiros em 14 de março de 2018, foi a personagem central de diversas informações falsas sobre sua atuação parlamentar e suposta ligação com o crime organizado e tráfico de drogas no Rio de Janeiro.

Figura 1- Reprodução de post de fake news sobre Marielle Franco

\section{QUEM ERA MARIELLE}

-Engravidou aos 16 anos.

-Ex-Mulher de Marcinho VP.

-Usuaria de maconha.

-Eleita pelo Comando Vermelho.

-Foi defender faccao rival no bairro

do Acari no RJ.

-Exonerou 6 funcionarios

recentemente.

\section{Mas quem a matou foi a Policia!!!}

Fonte: Monitor do debate político no meio digital (2018) 


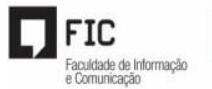

De acordo com Ribeiro e Ortellado (2018) na nota técnica \#2 divulgado pelo portal Monitor do debate político no meio digital, os boatos circularam primeiro pelo aplicativo WhatsApp, depois tiveram repercussão nas redes sociais como Facebook e Twitter e acabaram influenciando a agenda-setting ${ }^{5}$ dos veículos de comunicação.

A nota técnica indica que $67 \%$ das pessoas receberam a nota de fake news pelo aplicativo WhatsApp e, que nesse universo, $51 \%$ ocorreu por meio de grupo de familiares, seguido por $32 \%$ de grupos de amigos, $9 \%$ por grupos de colegas de trabalho e $9 \%$ por outros grupos ou mensagens diretas.

Outro dado relevante demonstrado pela nota técnica do Monitor do debate político no meio digital é que mesmo com supostas evidências como vídeos ou fotos, o maior alcance foi o conteúdo que apresentava apenas o texto sem qualquer acompanhamento.

Isso está de acordo com os estudos sobre viés de confirmação, isto é, nossa pouca capacidade de tratar criticamente informações que referendam ou confirmam nossas crenças. Menos importante do que as evidências que amparavam o boato foi o fato dele estar de acordo com as crenças das pessoas: no caso, o preconceito de que pessoas da favela tem vínculos com o tráfico de drogas. (RIBEIRO; ORTELLADO, 2018).

A ausência dessa capacidade crítica, como forma de constatação da padronização do comportamento dos usuários, pode ser observada, por exemplo, por meio da reprodução de post de pessoas com status social e que ocupam funções que, tecnicamente, são consideradas como portadores de uma capacidade acima da média da população.

Figura 2 - Postagem do deputado federal Alberto Fraga (DEM-DF)

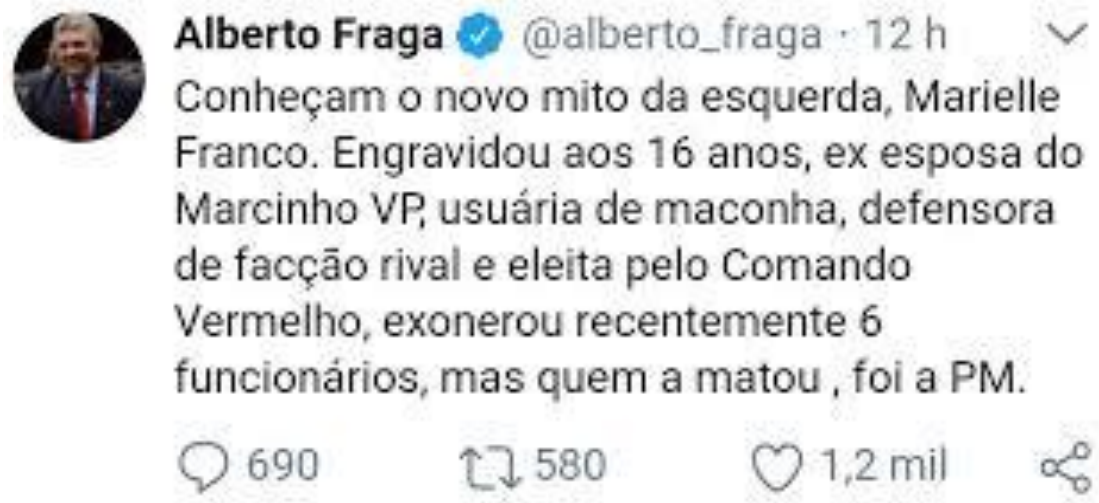

Fonte: Reprodução Twitter (2018).

\footnotetext{
${ }^{5}$ A teoria da agenda-setting elaborada por Maxwell McCombs e Donald Shaw, em 1972, refere-se ao processo de definição e intensidade de cobertura jornalística de um fato com base na relevância e interesse do público.
} 
Figura 3 - Comentário da desembargadora do Tribunal de Justiça do Rio de Janeiro Marilia Castro Neves

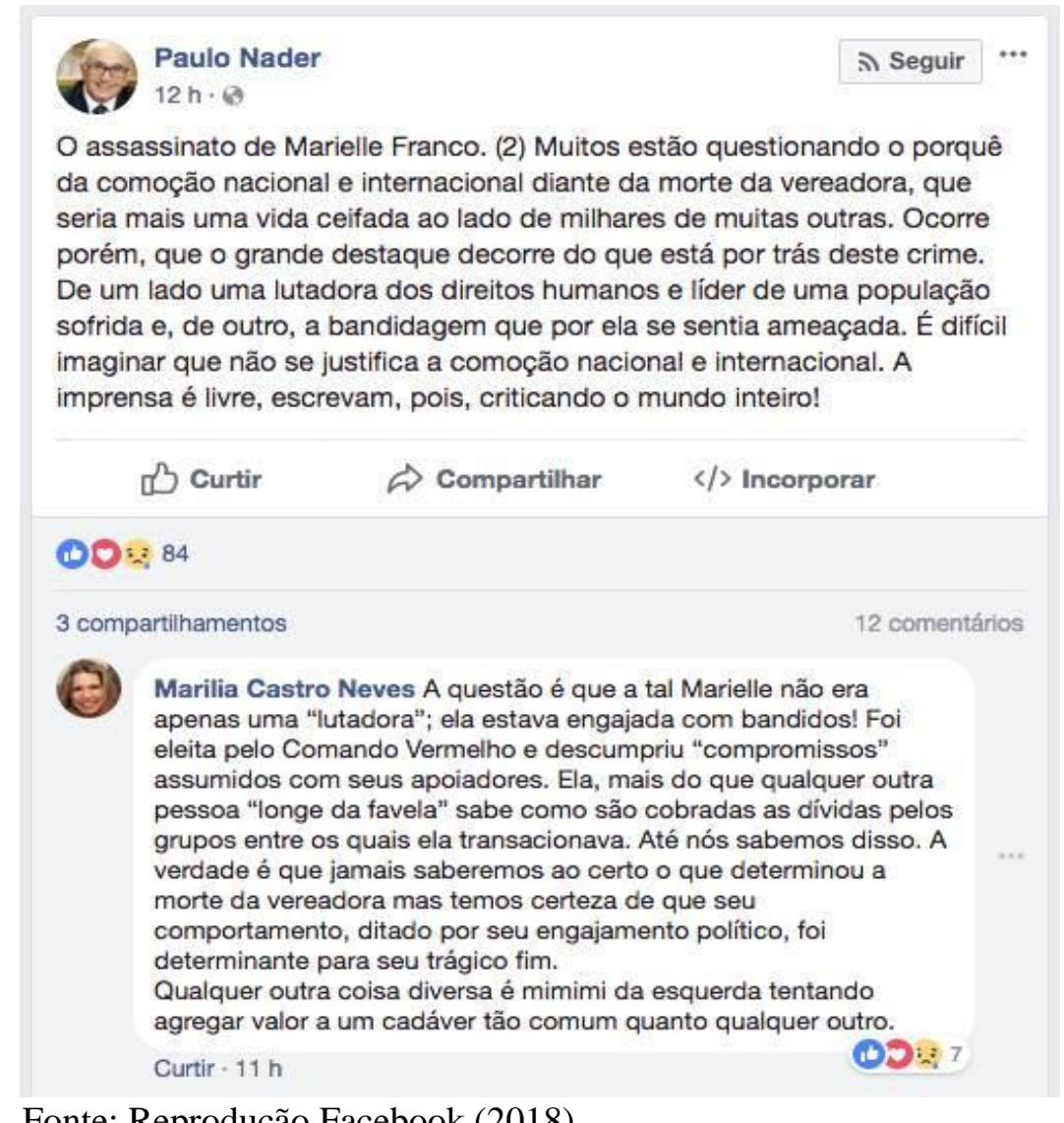

Fonte: Reprodução Facebook (2018)

A constatação desse comportamento padronizado, baseado em crenças e ideais mitificados, e da necessidade de participação no sistema de comunicação sobre temas em destaque nos grupos e comunidades virtuais, corrobora com os conceitos apresentados anteriormente e reforça o conceito de que esse fluxo de informação se traduz em um processo de socialização e de relação com o outro.

Nisso tudo, entram motivações utilitárias, práticas, intelectuais, mas também lúdicas, oníricas, que se esgotam em si mesmas. A comunicação pode ser, como nas conversas sem razão de ser de todo dia, um ato em si: conversar por conversar, para estar junto, para passar o tempo, para dividir um sentimento, uma emoção, um momento, um pequeno nada de cada dia. Comunicar por comunicar. A informação pode até ser vista como uma astúcia da comunicação. A pessoa olha um telejornal, em princípio para informar-se, mas, em realidade, toma-o como um espetáculo, um divertimento, um jogo de imagens. Depois, comenta os assuntos com amigos. A informação talvez nada tenha mudado em sua vida ou não tenha tido, para essa pessoa, nenhum valor efetivo, operacional, mas serviu de elo, de motivo para estar com outro, de assunto, de laço social. (MAFFESOLI, 2003, p. 17). 


\section{A INTERFERÊNCIA TECNOLÓGICA E O COMPORTAMENTO DO USUÁRIO}

Como mencionado anteriormente, o fluxo de comunicação é um reflexo da busca pelo processo de socialização e da criação de laços sociais por meio dos grupos e comunidades existentes no ciberespaço. Dessa forma, a tendência é que o usuário se adeque aos padrões, crenças e métodos predefinidos de uma forma intuitiva e com baixo índice de análise crítica, já que sua pretensão é ser visto e acolhido pelos demais membros.

Por outro lado, acreditamos que seja necessário considerar a interferência de mecanismos tecnológicos, que apesar de não serem determinantes, são responsáveis por elementos que fortalecem e direcionam os atos que levam ao impulsionamento da difusão de fake news pelos usuários das plataformas e mídias sociais.

Retomando a análise do caso envolvendo a vereadora Marielle Franco (PSOL-RJ), Ribeiro e Ortellado (2018) demonstram na nota técnica \#2 divulgada pelo portal Monitor do debate político no meio digital, que a informação ganhou maior impulsionamento por meio das mídias sociais como o Facebook.

Durante o acompanhamento da difusão da fake news, no período de 15/03/18 a 26/03/18, o documento registrou um crescimento de 10 a 15 vezes após o conteúdo ser compartilhado na mídia social, que demonstrou ser uma ferramenta de amplo alcance.

Foram necessários três ou quatro dias para o boato estar amplamente difundido e, no primeiro dia, o alcance foi muito pequeno. Essa dinâmica é bastante diferente daquela que vemos no Facebook onde a difusão se dá por uma espécie de explosão inicial e chega a seu alcance pleno em pouco mais de 48 horas. (RIBEIRO; ORTELLADO, 2018).

Figura 4 - Evolução da difusão da fake news sobre Marielle Franco

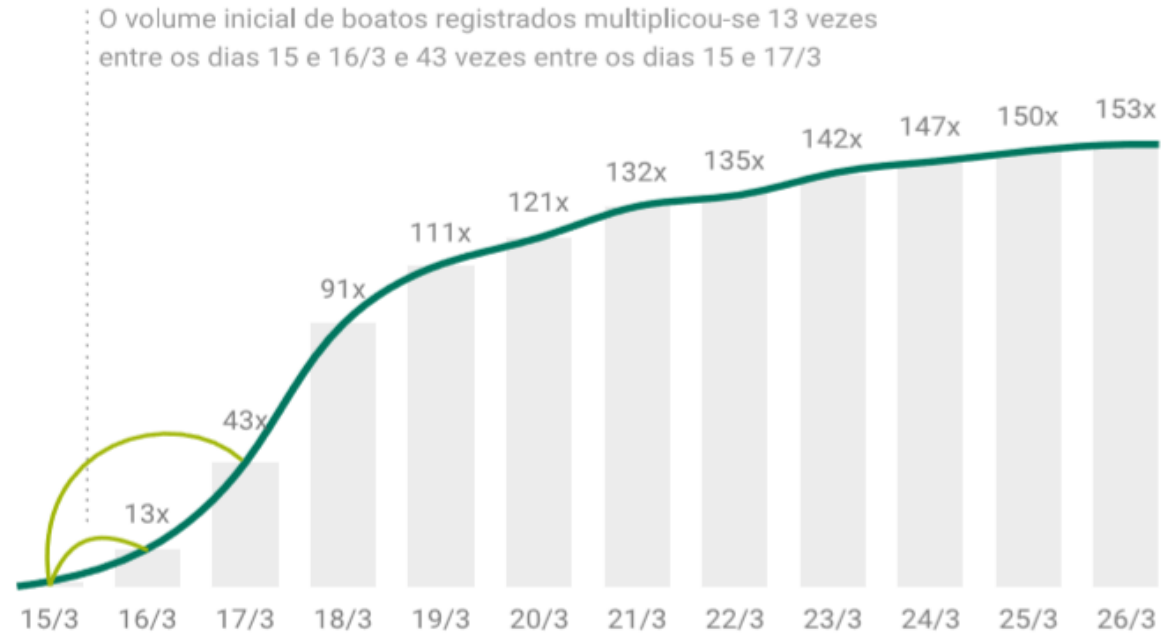

Fonte: Monitor do debate político no meio digital (2018). 
Por meio da Figura 4 é possível verificar que a ferramenta digital, nesse caso o Facebook, teve uma interferência direta no processo de difusão, que mesmo não sendo intencional potencializou os compartilhamentos do conteúdo.

Assim, conseguimos relacionar como a comunicação, no sentido de relação social observada por Maffesoli (2003), ganha amplitude ao explorar os padrões demonstrados pelos usuários. Isso ocorre em razão do processo envolvendo os algoritmos da mídia social que, por sua vez, gera um fenômeno delimitando o acesso a informação conceitualmente chamado de "filtro bolha".

A teoria do "filtro bolha", segundo Pariser (2011), envolve a ação de algoritmos que atuam como filtros no ambiente virtual. As características e dados selecionados alimentam motores de busca para direcionarem o acesso de conteúdo tomando como referência o perfil e os hábitos de consumo do usuário. Esse mecanismo, utilizado, por exemplo, pelo Facebook, acaba restringindo o alcance às diferentes fontes de informação, que, eventualmente, poderiam contradizer ou até esclarecer os fatos.

Esse efeito pode ser melhor compreendido pela visão de Manovich (2005, p. 283) que demonstra como os novos meios utilizam a base de dados que se fundamenta na experiência e nos hábitos do usuário para definir a relevância de conteúdos ou resultados de pesquisas de acordo com padrões pré-estabelecidos.

No entanto, do ponto de vista da experiência do usuário, em grande parte, esses são bancos de dados em um sentido mais básico. Eles aparecem como coleções de elementos nos quais o usuário pode executar várias operações, seja na aparência, navegação ou pesquisa. A experiência do usuário deste tipo de coleções informatizadas é, portanto, bem diferente de ler uma história, assistir a um filme ou navegar por um site de arquitetura. Da mesma forma, uma história literária ou cinematográfica, um plano arquitetônico e um banco de dados apresentam a cada um um modelo diferente do que o mundo é. É esse sentido do banco de dados como uma forma cultural por direito próprio que quero abordar aqui. (MANOVICH, 2005, p. 284, tradução nossa) ${ }^{6}$.

$\mathrm{O}$ contexto tecnológico narrado e considerando os aspectos envolvendo o comportamento do usuário, em relação ao fluxo de informações, comprovam a atuação desses efeitos no processo de comunicação nos ambientes virtuais.

\footnotetext{
${ }^{6}$ Sin embargo, desde el punto de vista de la experiencia del usuario, en una gran proporción se trata de bases de datos en un sentido más básico. Aparecen como coleciones de elementos sobre los que el usuario puede efectuar diversas operaciones, ya sea mirar, navegar o buscar. La experiencia del usuário de ese tipo de colecciones informatizadas es, por tanto, bastante distinta de la de leer un relato, ver una película o navegar por un sitio de arquitectura. De la misma manera, una historia literaria o cinematográfica, un plan arquitectónico y una base de datos presentan cada uno de ellos un modelo diferente de lo que es el mundo. Es este sentido de la base de datos en cuanto forma cultural por derecho próprio el que quiero abordar aquí. (MANOVICH, 2005, p. 284).
}

Comun. \& Inf., Goiânia, GO, v. 21, n. 3, p. 91-106, out./dez. 2018. 
Isso ocorre por meio da construção ideológica, muitas vezes imperceptível por parte do público, que condiciona a forma de atuação e fortalece a continuidade de ações e reações que induzem a mitificação e reprodução de tendências que Eco (2004) classificou como sendo o "homem heterodirigido".

Um homem heterodirigido é um homem que vive numa comunidade de alto nível tecnológico e particular estrutura social e econômica (nesse caso baseado numa economia de consumo), e a quem constantemente se sugere (através da publicidade, das transmissões de TV, das campanhas de persuasão que agem sobre todos os aspectos da vida cotidiana) o que deve desejar e como obtê-lo segundo certos canais pré-fabricados que o isentam de projetar perigosamente e responsavelmente. Numa sociedade desse tipo a própria opção ideológica é "imposta" através de um cauteloso controle das possibilidades emotivas do eleitor, e não promovida através de um estímulo à reflexão e à avaliação racional. (ECO, 2004, p. 261).

\section{CONSIDERAÇÕES FINAIS}

A relação entre o comportamento do usuário e a interferência dos mecanismos prédefinidos pelas novas tecnologias é uma ocorrência incontestável. No entanto, é importante ressaltar que os "filtros" provocados pelos algoritmos e programações apenas restringem o universo de informações e não aceleram a difusão desse conteúdo.

De acordo com Vosoughi, Roy e Aral (2018), as novas tecnologias favorecem um efeito cascata que intensifica o alcance por meio de microgrupos, que repetem as mesmas ações baseadas em informações e características pré-definidas pelos seus usuários.

Embora se possa esperar que a estrutura da rede e as características individuais dos espalhadores favoreçam e promovam notícias falsas, o contrário é verdadeiro. A maior probabilidade de as pessoas retomar a falsidade mais do que a verdade é o que impulsiona a propagação de falsas notícias, apesar da rede e fatores individuais que favorecem a verdade. Além disso, embora o recente testemunho antes dos comitês do Congresso sobre desinformação nos Estados Unidos tenha se concentrado no papel dos bots na divulgação de falsas notícias, concluímos que o comportamento humano contribui mais para a disseminação diferencial da falsidade e da verdade do que os robôs automatizados. Isso implica que políticas de contenção de desinformação também devem enfatizar intervenções comportamentais, como rotulagem e incentivos para dissuadir a disseminação de informações errôneas, em vez de se concentrar exclusivamente na redução de bots. (VOSOUGHI; ROY; ARAL, 2018, tradução nossa) ${ }^{7}$

\footnotetext{
${ }^{7}$ Though one might expect network structure and individual characteristics of spreaders to favor and promote false news, the opposite is true. The greater likelihood of people to retweet falsity more than the truth is what drives the spread of false news, despite network and individual factors that favor the truth. Furthermore, although
}

Comun. \& Inf., Goiânia, GO, v. 21, n. 3, p. 91-106, out./dez. 2018. 
Esse comportamento, que muitas vezes pode ser confundido com uma ação deliberada e intencional, na verdade é compreendido por meio da percepção que o motivador do compartilhamento seja exatamente a reprodução de atos em busca da participação no grupo e posicionamento social.

Com base em Maffesoli (2004), essas características demonstram um reflexo da sociedade pós-moderna que se configura em uma estrutura de identificações múltiplas e não mais na identidade, o que favorece a existência de microconjuntos e de formas comunitárias.

O autor aponta que a condição de indivíduo passou a dar espaço para as "afinidades eletivas", ou seja, as crenças, posicionamentos e hábitos são influenciados diretamente pelo grupo e as ações são direcionadas para atender esses padrões.

\footnotetext{
É aí que a ideia de autonomia, que era constitutiva da modernidade, cede lugar a outra coisa. Poderíamos falar de heteronomia, que designa o fato de que eu não seria mais a minha própria lei. Minha lei é outra. Eu existo somente no e para o espírito do outro, somente no e para o olhar do outro. O "se tornar moda no mundo" é, nesse aspecto, interessante: moda da vestimenta, moda da linguagem, moda corporal, moda sexual. [...] Ao contrário do contrato com o seu aspecto racional, voluntário, que comporta essa noção, está se constituindo uma outra maneira de ser, uma outra forma de socialidade. Essa outra maneira de ser vai reinvestir os elementos que a análise social tinha deixado de lado: $o$ emocional e o afetual. $\mathrm{O}$ afetual e o emocional não são unicamente da ordem do emotivo ou do afetivo, mas um clima específico baseado nos processos de contaminação, no fato de que toda uma série de "transes", às vezes macroscópicos, frequentemente microscópicos, constitui o terreno da vida social. (MAFFESOLI, 2004, p. 28).
}

Diante do exposto consideramos que a fake news é um fenômeno social que teve seus efeitos e impactos ampliados em decorrência das novas tecnologias, mas que sua difusão ainda tem como principal caraterística a ação do usuário, já que como observado por Vosoughi, Roy e Aral (2018), ao contrário do senso comum, os recursos tecnológicos como robôs e algoritmos, difundem notícias verdadeiras e falsas no mesmo ritmo.

Nesse sentido, retomamos o conceito do "além-homem" de Nietzsche que toma uma posição de desafio para a sociedade na pós-modernidade, ou seja, a necessidade do indivíduo rever conceitos e padrões pré-definidos, além de desenvolver uma postura crítica para que seja

recent testimony before congressional committees on misinformation in the United States has focused on the role of bots in spreading false news, we conclude that human behavior contributes more to the differential spread of falsity and truth than automated robots do. This implies that misinformation-containment policies should also emphasize behavioral interventions, like labeling and incentives to dissuade the spread of misinformation, rather than focusing exclusively on curtailing bots. (VOSOUGHI; ROY; ARAL, 2018) 
possível compreender os mecanismos tecnológicos e, a partir disso, ter condições de amenizar ou reduzir os impactos dos filtros.

Essa perspectiva, que aparentemente simboliza um ideal utópico, é uma condição essencial para o combate nas causas de um problema em que se discute os efeitos provocados por meio dos mecanismos de difusão. Afinal, segundo Nietzsche (2005a, p. 211), "o que é grande no homem é que ele é uma ponte e não um fim $[\ldots]$ ”.

\section{REFERÊNCIAS}

CASTELLS, M. A sociedade em rede: a era da informação - economia, sociedade e cultura. 6. ed. São Paulo: Paz e Terra, 2005.

ECO, U. Apocalípticos e integrados. 6. ed. São Paulo: Perspectiva, 2004.

LOPES, G. Vídeos mostram fábricas de ovos falsos de plástico! Será verdade? E-farsas, 25 jun. 2018. Disponível em: <http://www.e-farsas.com/videos-mostram-fabricas-de-ovosfalsos-sera-verdade.html>. Acesso em 3 jul. 2018.

MAFFESOLI, M. A comunicação sem fim (teoria pós-moderna da comunicação). Revista FAMECOS, Porto Alegre, n. 20, p.13-20, abr. 2003. Disponível em: $<$ http://revistaseletronicas.pucrs.br/ojs/index.php/revistafamecos/article/view/3198>. Acesso em 3 jul. 2018.

Perspectivas tribais ou a mudança do paradigma social. Revista FAMECOS, Porto Alegre, n. 23, p.23-29, abr. 2004. Disponível em:

$<$ http://revistaseletronicas.pucrs.br/ojs/index.php/revistafamecos/article/view/3247>. Acesso em 3 jul. 2018.

MANOVICH, L. El lenguaje de los nuevos medios de comunicación: la imagen en la era digital. Barcelona: Paidós, 2005.

MATSUKI, E. Nova greve dos caminhoneiros começa na segunda-feira e será mais violenta. Boatos.org, 24 jun. 2018. Disponível em: <http://www.boatos.org/brasil/nova-grevecaminhoneiros-segunda-feira.html>. Acesso em 3 jul. 2018.

Ovos de plástico da China chegaram ao Brasil, mostra vídeo. Boatos.org, 26 jun. 2018. Disponível em: <http://www.boatos.org/saude/ovos-plastico-china-chegarambrasil.html>. Acesso em 3 jul. 2018.

NIETZSCHE, F. Assim falou Zaratrustra: um livro para todos e ninguém. São Paulo: Nova Cultura, 2005a. . p. 209-249. Coleção Os Pensadores.

Assim falou Zaratrustra: um livro para todos e ninguém. Tradução de José Mendes de Souza. Rio de Janeiro: Ediouro, 1984. 
A filosofia na época trágica dos gregos (1873). São Paulo: Nova Cultura, 2005b. p. 251-300. Coleção Os Pensadores.

PARISER, E. The filter bubble: what the internet is hiding from you. Nova Iorque: The Pinguim Press, 2011.

RIBEIRO, M. M.; ORTELLADO, P. Nota técnica \#2 - A difusão dos boatos sobre Marielle Franco: do WhatsApp aos sites de notícias. Monitor do debate político no meio digital, 24 abr. 2018. Disponível em <http://www.monitordigital.org/wp-content/uploads/NOTATECNICA-2.pdf>. Acesso em 3 jul. 2018.

VOSOUGHI, S.; ROY, D.; ARAL, S. The spread of true and false news online. Science, Washington (USA), v. 359, n. 6380, p. 1146-1151, 9 mar. 2018. Disponível em:

<http://science.sciencemag.org/content/359/6380/1146.full> . Acesso em: 11 mar. 2018. 